\title{
Non-invasive Central and Peripheral Stimulation: New Hope for Essential Tremor?
}

\author{
Moussa A. Chalah ${ }^{1,2}$, Jean-Pascal Lefaucheur ${ }^{1,2}$ and Samar S. Ayache ${ }^{1,2,3 *}$ \\ ${ }^{1}$ EA 4391, Excitabilité Nerveuse et Thérapeutique, Université Paris-Est-Créteil, Créteil, France, ${ }^{2}$ Service de Physiologie - \\ Explorations Fonctionnelles, Hôpital Henri Mondor, Assistance Publique - Hôpitaux de Paris, Créteil, France, ${ }^{3}$ Neurology \\ Division, University Medical Center Rizk Hospital, Beirut, Lebanon
}

OPEN ACCESS

Edited by:

Ignacio Obeso,

CEU San Pablo University, Spain

Reviewed by:

Guglielmo Foffani,

Drexel University, USA

Lydia Vela,

Hospital Universitario Fundación Alcorcón, Spain

*Correspondence:

Samar S. Ayache

samarayache@gmail.com

Specialty section:

This article was submitted to

Neurodegeneration,

a section of the journal

Frontiers in Neuroscience

Received: 17 July 2015 Accepted: 01 November 2015 Published: 18 November 2015

Citation:

Chalah MA, Lefaucheur J-P and Ayache SS (2015) Non-invasive Central and Peripheral Stimulation: New Hope for Essential Tremor?

Front. Neurosci. 9:440. doi: 10.3389/fnins.2015.00440
Essential tremor (ET) is among the most frequent movement disorders. It usually manifests as a postural and kinematic tremor of the arms, but may also involve the head, voice, lower limbs, and trunk. An oscillatory network has been proposed as a neural correlate of ET, and is mainly composed of the olivocerebellar system, thalamus, and motor cortex. Since pharmacological agents have limited benefits, surgical interventions like deep brain stimulation are the last-line treatment options for the most severe cases. Non-invasive brain stimulation techniques, particularly transcranial magnetic or direct current stimulation, are used to ameliorate ET. Their non-invasiveness, along with their side effects profile, makes them an appealing treatment option. In addition, peripheral stimulation has been applied in the same perspective. Hence, the aim of the present review is to shed light on the emergent use of non-invasive central and peripheral stimulation techniques in this interesting context.

Keywords: essential tremor, tremor, tDCS, rTMS, TBS, TENS, non-invasive brain stimulation

\section{INTRODUCTION}

Essential tremor (ET) is among the most frequent movement disorders in individuals above 40 years of age (Louis et al., 1995; Dogu et al., 2003). Clinically, it manifests as postural and action tremor of the arms, but may also involve the head, voice, lower limbs, and trunk (Deuschl et al., 1998; Bain et al., 2000; Elble, 2000; Raethjen and Deuschl, 2012). From an etiological perspective, it is classified as sporadic or hereditary (Kuhlenbäumer et al., 2014). Despite its high prevalence, its underlying pathophysiological mechanisms are still not well elucidated. Data from neuroimaging and neurophysiological studies have put into evidence the existence of a cerebello-thalamo-cortical (CTC) network for ET (Pinto et al., 2003; Popa et al., 2013; Hallett, 2014). The latter includes the sensorimotor cortex, olivocerebellar system, red nucleus, and thalamus (Colebatch et al., 1990; Jenkins et al., 1993; Hallett and Dubinsky, 1993; Wills et al., 1995; Bucher et al., 1997; Boecker and Brooks, 1998; Deuschl et al., 2000; Pinto et al., 2003; Raethjen et al., 2007; Quattrone et al., 2008; Shin et al., 2008; Schnitzler et al., 2009; Cerasa et al., 2010; Park et al., 2010; Bagepally et al., 2012; Paris-Robidas et al., 2012; Raethjen and Deuschl, 2012; Fang et al., 2013; Buijink et al., 2015; Choi et al., 2015; Shin et al., 2015). The presence of such a circuit was further confirmed by reports documenting ET disappearance following strokes that involved some of its components (Dupuis et al., 2010; Lim et al., 2010; Chalah et al., 2015).

Although ET is commonly thought to be a benign condition, affected patients represent a heterogeneous population (Louis, 2009) and severe cases could be very disabling (Louis, 2005). 
In this context, pharmacological agents have yielded modest benefits (Findley, 1987; Louis, 2000; Deuschl et al., 2011), and non-adherence to ET medications has been reported (Louis, 2015). Surgical interventions, like the deep brain stimulation, are the last-line treatment options for the most severe cases (Chopra et al., 2013). However, they have some limitations related to their cost and potential side effects (Grimaldi and Manto, 2008). Nowadays, there is a growing interest in using non-invasive central and peripheral stimulation techniques as alternatives to pharmacological and surgical interventions. Hence, in the present review, we shed light on the emergent use of these techniques in treating ET. Conversely, we excluded all data regarding invasive interventions, namely cortical, or deep brain stimulation.

\section{PRINCIPLES OF NON-INVASIVE BRAIN STIMULATION TECHNIQUES}

In the recent years, two non-invasive brain stimulation (NIBS) techniques, i.e., repetitive transcranial magnetic stimulation (rTMS) and transcranial direct current stimulation (tDCS), gained interest for their potential implication in treating various neuropsychiatric symptoms (Kuo et al., 2014; Lefaucheur et al., 2014). These techniques are based on different principles.

To start, rTMS consists of a transcranial delivery of an electromagnetic field by a stimulation coil positioned on the patient's scalp. The induced intracortical current is strong enough to trigger action potentials according to Faraday's law of electromagnetic induction (Lefaucheur, 2012). Thus, it acts by modulating the cortical excitability in a frequency-dependent manner, as low (LF) and high (HF) stimulation frequencies $(<1$ vs. $>5 \mathrm{~Hz})$ have been shown to induce inhibitory and excitatory effects, respectively (Lefaucheur et al., 2014). Other than the frequency, various stimulation parameters, such as the selected cortical target, can influence the clinical effects of rTMS (Lefaucheur, 2008, 2009, 2012).

In addition to rTMS, new stimulation paradigms are being developed, of which theta burst stimulation (TBS) is the most popular (Lefaucheur, 2009). Practically, TBS consists of short bursts delivered at $5 \mathrm{~Hz}$ (within the theta range), each burst consisting of three magnetic pulses delivered at $\mathrm{HF}(50 \mathrm{~Hz})$. TBS is either applied continuously (cTBS) for $40 \mathrm{~s}$ or intermittently (iTBS) during $2 \mathrm{~s}$ every $10 \mathrm{~s}$ for a total stimulation time of 200 s. Similar to rTMS, the action of TBS primarily depends on the stimulation pattern: cTBS and iTBS respectively induce long-term synaptic depression-like and potentiation-like effects, when applied over the primary motor cortex (M1) of healthy individuals (Huang et al., 2005, 2007; Teo et al., 2007; Huang, 2010; Wischnewski and Schutter, 2015).

Beside magnetic stimulation, tDCS has emerged as a promising neuromodulatory technique. It consists of delivering an electric current of low intensity (1-2 mA) over few minutes via two electrodes (anode and cathode) positioned over the scalp. By doing so, it could induce prolonged yet reversible shifts in cortical excitability and might modulate the connectivity of various neural circuits (Priori et al., 1998; Nitsche and Paulus, 2000, 2001;
Priori, 2003; Nitsche et al., 2003a). The polarity of tDCS protocols determines the neurophysiological outcomes at the level of the exposed tissues: a depolarization or a hyperpolarization of the resting membrane potentials would occur following anodal or cathodal tDCS, respectively (Creutzfeldt et al., 1962; Purpura and McMurtry, 1965; Nitsche and Paulus, 2011; Paulus et al., 2013; Filmer et al., 2014). Several parameters mainly related to the electrodes properties (size, polarity, position), the used current (strength and shape), and the stimulation duration, can account for the tDCS effects (Creutzfeldt et al., 1962; Nitsche and Fregni, 2007; Nitsche et al., 2008). tDCS is safe, easily performed, welltolerated by the patients with little or no side effects (Poreisz et al., 2007; Nitsche et al., 2008; Brunoni et al., 2012), and presents an easier and indistinguishable implementation of sham sessions compared to rTMS protocols (Gandiga et al., 2006).

\section{FUNCTIONAL UNDERPINNINGS OF ESSENTIAL TREMOR}

Quite before their therapeutic implications, NIBS techniques have been used to explore the cortical excitability in various pathologies. For example, using transcranial electrical stimulation, one study has shown a normal central motor conduction time in four ET patients, from a series of patients with various movement disorders (Thompson et al., 1986). Using transcranial magnetic stimulation, another study has revealed normal patterns of cortical excitability in ET patients, as expressed by motor thresholds and motor evoked potentials amplitude (Romeo et al., 1998). In other works, ET patients exhibited normal patterns of intracortical inhibition (Hanajima et al., 1998; Romeo et al., 1998; Shukla et al., 2003; Chuang et al., 2014) and cerebello-thalamo-cortical inhibition (Pinto et al., 2003); the latter is a neurophysiological parameter that reflects the degree of reduction of the motor cortical output via the activation of cerebellar inhibitory projections (Pinto and Chen, 2001).

It was not until recently that cortical excitability studies have unveiled abnormal CTC functioning in patients with ET (Chuang et al., 2014; Bologna et al., 2015). Such results are of particular interest since they are in line with functional neuroimaging studies which revealed altered patterns of cortical activation and inter-regional connectivity within the CTC pathways and nonmotor cortices (Wills et al., 1995; Bucher et al., 1997; Cerasa et al., 2010; Passamonti et al., 2011; Fang et al., 2013; Popa et al., 2013; Buijink et al., 2015).

In light of this evidence, the neurotransmitters imbalance has been speculated to contribute to the pathophysiology of ET. In this perspective, the glutamatergic metabolism has lately received some attention, but genetic studies have revealed controversial outcomes (Thier et al., 2012; García-Martín et al., 2013; Tan et al., 2013; Yu et al., 2013; Ross et al., 2014). The role of dopamine was also assessed in a number of studies that tried anti-psychotics (Pakkenberg and Pakkenberg, 1986; Ceravolo et al., 1999; Micheli et al., 2002; Yetimalar et al., 2003, 2005) and dopaminergic drugs (Koller, 1981; Manyam, 1984; Gironell et al., 2006) in ET management; tremor improvement was only 
observed in the two studies involving olanzapine (Yetimalar et al., 2003, 2005). Additionally, multidisciplinary studies are supporting the role of an aberrant GABAergic transmission in ET production (Louis, 1999; Zesiewicz et al., 2007, 2013; Boecker et al., 2010; Gironell et al., 2012; Paris-Robidas et al., 2012; Shill et al., 2012; Boecker, 2013; Helmich et al., 2013; Chuang et al., 2014; Gironell, 2014; Schneider and Deuschl, 2014). Therefore, acting on such a neurochemical imbalance might be helpful in improving ET. Interestingly, some studies have reported that NIBS after-effects take place through the modulation of the glutamatergic, GABAergic and dopaminergic transmissions (Liebetanz et al., 2002; Nitsche et al., 2003b, 2006; Stagg et al., 2009; Monte-Silva et al., 2011; Foerster et al., 2015). In addition, studies coupling NIBS techniques with functional neuroimaging have shown that rTMS, TBS, and tDCS are able to improve the functional connectivity of various cortico-subcortical networks (Bestmann et al., 2004; Grefkes et al., 2010; Eldaief et al., 2011; Keeser et al., 2011; Polanía et al., 2011, 2012a,b; Halko et al., 2014; Valchev et al., 2015).

Taken together, these data suggest that NIBS techniques would ameliorate ET by (i) acting on the neurochemical imbalance at the site of stimulation, (ii) subsequently modulating the local cortical excitability and by doing so, (iii) restoring the functional integrity of the CTC network of ET.

\section{NIBS STUDIES AND ESSENTIAL TREMOR}

Early neurophysiological studies have assessed the role of NIBS techniques in modulating the physiological parameters in ET. Single-pulse TMS over M1 was successively able to reset ongoing tremor activity (Britton et al., 1993a; Pascual-Leone et al., 1994; Yu et al., 2001). In a recent study, ET resetting resulted from applying single-pulse or paired-pulse TMS over M1 or the supplementary motor area (SMA), but not over the cerebellum (Lu et al., 2015).

Electrical stimulation was also used in the same setting. Although early reports have documented a failure of transcranial motor electrical stimulation in resetting ET (Pascual-Leone et al., 1994), a new study have provided evidence regarding the ability of transcranial alternating current stimulation to induce tremor entrainment when applied over the cerebellum of ET patients (Brittain et al., 2015).

These data altogether have pushed the research toward studying the possible therapeutic implementations of NIBS in terms of ET. A PubMed search using the keywords rTMS/TBS/tDCS and essential tremor has identified seven English papers. Their designs and outcomes are reported in Table 1.

\section{rTMS and Essential Tremor}

The first published study involved 10 patients with ET of the upper limbs, in a double-blind, crossover, and sham-controlled design (Gironell et al., 2002). The patients received two sessions of either active or sham $1 \mathrm{~Hz}$ rTMS over the cerebellum separated by 1 -week free interval. Compared to sham, significant shortterm effects were observed following real rTMS session, as expressed by the improvement of the tremor clinical rating scale and tremor frequency on accelerometric studies. However, such an improvement did not last more than $5 \mathrm{~min}$ following the session.

In a second study, $11 \mathrm{ET}$ patients underwent a single session of $1 \mathrm{~Hz}$ rTMS over the cerebellum to evaluate the potential modulation of motor behavior during repetitive finger tapping movements of the right hand using a sensor-engineered glove (Avanzino et al., 2009). Seven patients also received sham session at least 2 weeks apart from the real one. Compared to healthy controls, ET patients presented lower inter-tapping interval (ITI), increased coefficient of variation of ITI (ITICV), and longer touch duration (TD). The latter represents the time when the thumb and another finger are in contact, before their separation which results in generation of the rhythmic movement. It is probably the sum of the time required for the thumb to get an adequate perception of another touched finger (sensory time), and the time needed to plan for the next movement (preparatory time), and by doing so, to maintain the rhythmic tapping (Georgiou et al., 1995). The cerebellum participates in the timing of movement and sensation (Rao et al., 2001), and increased ITICV was previously reported in the context of ET (Farkas et al., 2006). In the absence of sensory deficits in ET patients (Nahab et al., 2007), the abnormal TD values hint toward pathological phenomena at the level of sensorimotor integration, where the sensory information is used for the initiation of motor planning (Avanzino et al., 2009). In this study, rTMS reduced the TD values and normalized the ITI/ITICV values in ET patients in a transient manner. However, in contrast to the first study by Gironell et al. (2002), $1 \mathrm{~Hz}$ rTMS was unable to modify the frequency or the intensity of ET, which might be explained in part by the lower stimulation intensity adopted in this study.

A third study included eleven ET patients and eleven healthy controls (Popa et al., 2013). Here, the resting-state functional connectivity (rs-FC) of the CTC circuits and default brain network (DBN) was assessed before and after the application of five consecutive daily sessions of $1 \mathrm{~Hz}$ rTMS over the posterior cerebellar cortex. Stimulation was performed using a neuronavigation system to target the lobule VIII of both cerebellar hemispheres. Tremor was assessed using clinical scales and accelerometric recordings. A significant improvement was observed on clinical scales, and was associated with a reduction in tremor amplitude, but not frequency. This improvement persisted for 3 weeks after the last rTMS session and was associated with a near-normal restoration of the connectivity within the CTC network, but not within the DBN. These findings could reflect pronounced neuroplasticity effects that might have resulted from the repetition of the stimulation sessions. In addition, unlike the two previous studies, this one adopted a neuronavigation-guided paradigm, which might have an important role in optimizing rTMS protocols (Lefaucheur, 2010).

\section{TBS and Essential Tremor}

Two studies have applied cTBS over the motor and premotor cortices which are the key elements for movement preparation, selection, and execution. The first one assessed the effects of cTBS on tremor and cortical excitability in 10 patients with ET 


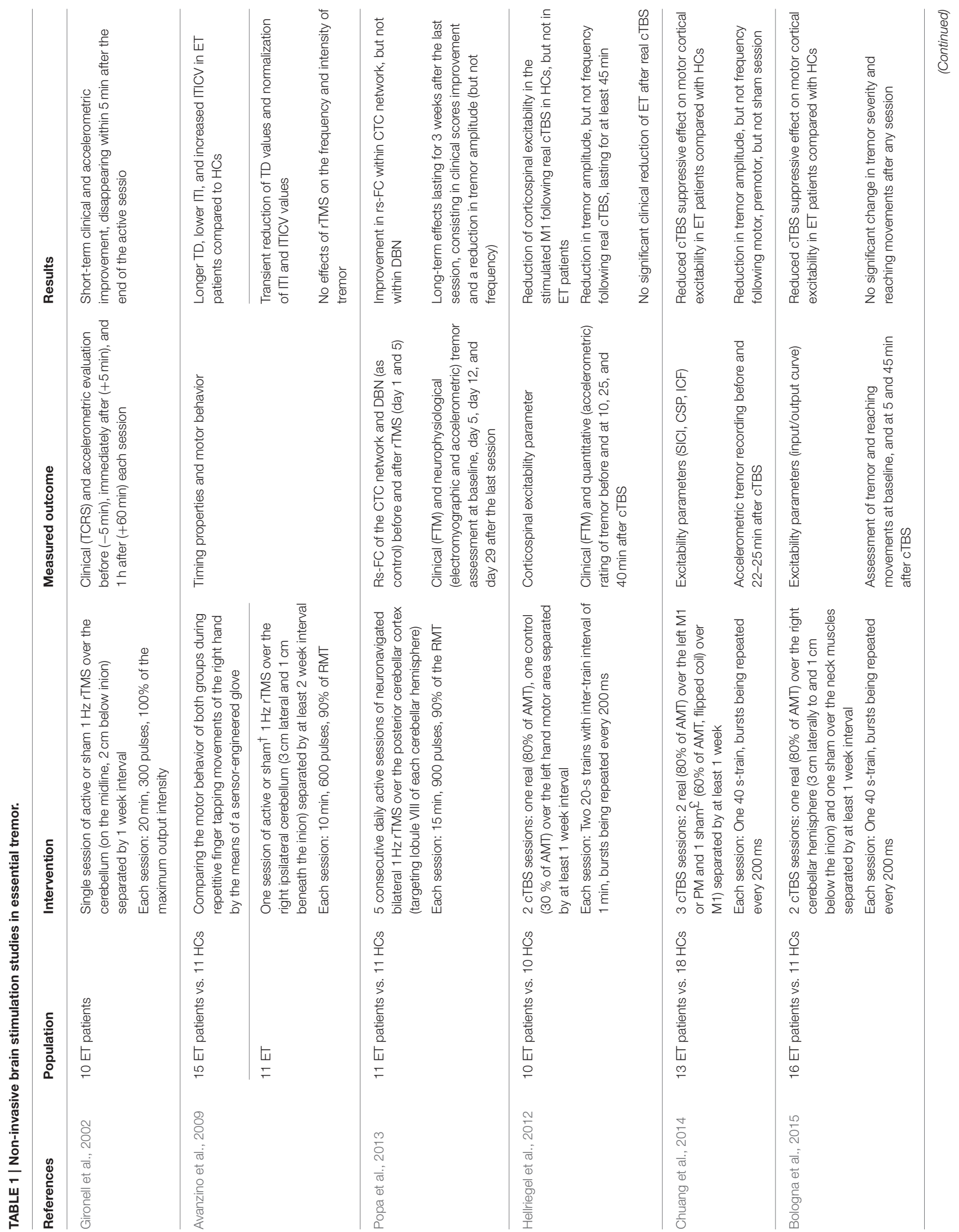




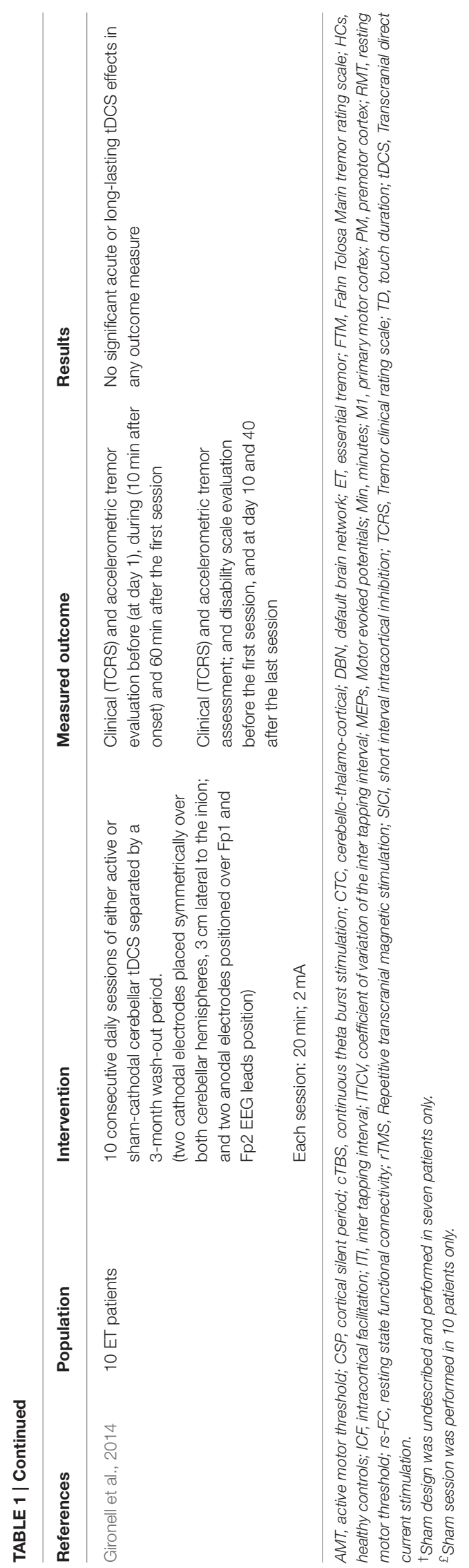

and 10 healthy controls (Hellriegel et al., 2012). Each participant randomly received two sessions of real or control cTBS over the left hand motor area separated by at least 1 week. A subclinical reduction in tremor amplitude, but not frequency, was observed following real cTBS session and lasted for at least $45 \mathrm{~min}$. Hereby, the absence of significant clinical improvement could be justified by the logarithmic relationship between accelerometric and clinical tremor assessment (Elble et al., 2006). In line with the first study, a second cTBS study has found an exclusive reduction in tremor amplitude following cTBS delivered to the motor and premotor cortices in 13 patients with ET (Chuang et al., 2014).

Interestingly, in both studies, motor cortical, or corticospinal excitability was assessed using different variables (Table 1); and it was shown that the suppressive cTBS effects on cortical excitability was either reduced or absent in ET patients compared to healthy controls. This suggests that the observed improvement in tremor amplitude appears to be independent of the modulation of the corticospinal motor output. Such observation is in accordance with recent evidence hinting toward the occurrence of cTBS-induced behavioral or rs-FC changes, unrelated to those of cortical excitability (Silvanto et al., 2007; Gentner et al., 2008; Nettekoven et al., 2014).

The third cTBS study was a randomized, sham-controlled, double-blind study that assessed the effects of right cerebellar cTBS in ET patients and healthy controls (Bologna et al., 2015). The authors did not find any effect of cTBS on clinical or kinematic measures of tremor. However, as in the two previously published trials, the suppressive effects of cTBS on cortical excitability were lost in ET patients compared to their healthy counterparts.

\section{tDCS and Essential Tremor}

Similar to rTMS, the ability of tDCS to modulate the cerebellar excitability has been previously reported (Galea et al., 2009). Gironell and colleagues have studied the effects of cathodal cerebellar tDCS in ten patients with ET (Gironell et al., 2014). Each patient randomly received two blocks, each consisting of 10 consecutive sessions of either active or sham bilateral cerebellar tDCS separated by at least 3 months of washout interval. Clinical and accelerometric studies did not reveal any short-term or longterm benefits following the real tDCS sessions. However, this study suffers from some limitations related to the small sample size and the high intra-subject variability of accelerometric measures.

\section{Peripheral Stimulation and Essential Tremor}

Besides trying to act at the level of the central oscillators, an alternative would be to focus on the ET substrates in charge of transmitting and displaying the symptom, namely the peripheral nerves and muscles. The efficacy of symptomatic interventions was tested in tremulous patients regardless of the tremor origin.

\section{Transcutaneous Electrical Nerve Stimulation}

Transcutaneous electrical nerve stimulation (TENS) is a noninvasive, cheap, and safe technique that consists of delivering 
an electrical current at various frequencies, intensities and pulse duration on a limited skin surface (Sluka and Walsh, 2003; Lim et al., 2010). TENS can modulate motor cortex excitability by acting on the sensory afferent input and the sensorimotor integration at the cortical level (Tinazzi et al., 2005a). In clinical practice, TENS is mainly applied to treat pain syndromes of various origins. In the field of movement disorders, TENS was also found to have some efficacy in dystonic tremor (Bending and Cleeves, 1990), writer's cramp dystonia (Tinazzi et al., 2005b, 2006), and psychogenic movement disorders (Ferrara et al., 2011).

As for ET, the first study to assess the effects of peripheral nerve stimulation was reported by Britton et al. (1993b). Here, the application of supramaximal median nerve shocks at the elbow ( $0.5 \mathrm{~ms}$ square-wave electrical pulse applied as five stimuli, randomly delivered at $5-8 \mathrm{~s}$ of interval; with sufficient intensity able to produce maximal EMG responses at the flexor carpi radialis) was able to cause acute inhibition, then synchronization of the EMG activity in 10 patients with ET, nine patients with Parkinson's disease (PD) tremor and nine healthy controls mimicking wrist tremor.

In another study, Munhoz and colleagues assessed TENS effects in five patients with ET and two patients suffering from tremor attributed to peripheral neuropathies (Munhoz et al., 2003). For this purpose, the cathode was placed over the brachial plexus with the reference electrode over the $\mathrm{C} 7$ spinous process. A 15-min stimulation was performed, using different settings (frequencies: 5, 10, 50, and $100 \mathrm{~Hz}$; one side vs. the other side vs. both sides simultaneously). No significant improvement was observed at any endpoint (accelerometric variables, tremor rating, and self-reported impression scales) (Munhoz et al., 2003).

\section{Functional Electrical Stimulation}

Another alternative to alleviate tremor would be through performing muscular contraction either voluntarily (Dietz et al., 1974; Héroux et al., 2010), or through neurostimulation using the so-called "closed-loop functional electrical stimulation" (FES) (Elek and Prochazka, 1989; Javidan et al., 1990, 1992; Prochazka et al., 1992; Gillard et al., 1999). The earliest study was performed by Javidan and colleagues and involved three patients with ET, four patients with $\mathrm{PD}$ and six patients with multiple sclerosis (MS) suffering from cerebellar tremor (Javidan et al., 1992). The authors documented attenuation in tremor amplitude by $73 \%$ in ET, $62 \%$ in PD, and $38 \%$ in MS. Interestingly, a minor shift in tremor frequency was observed in MS group, without any changes in ET or PD patients.

In an attempt to counteract tremor, this method consists of monitoring joint displacement using a miniature displacement transducer. The next step is to use the signals acquired from the joint angle excursions to perform an out-of-phase stimulation, in order to activate the antagonist muscle during involuntary activation of the agonist one. Counteracting tremor is possible via a feedback filter with bandpass characteristics designed to selectively attenuate tremor $(2-5 \mathrm{~Hz})$ while barely affecting the slow voluntary movements. Unfortunately, such a technique has some limitations. For instance, the FES ability to act on a given antagonistic pair restricts its role in patients with
ET where the symptom is often multidirectional and involves multiple joints. In addition, there is still uncertainty regarding the optimal way of electrodes positioning aiming to stimulate specific muscle groups. Moreover, despite the positive outcome of the preliminary study by Javidan et al. (1992), there is an intraindividual variation in tremor amplitude and frequency, which might limit the efficacy of FES to a specific frequency range and hence requires repeated calibrations of the feedback filter (Javidan et al., 1992). Furthermore, a certain degree of discomfort and fatigue might result from applying the phasic electrical stimulation, which makes the technique less appropriate for daily life usage. In this view, many FES studies have suggested some solutions to circumvent the faced difficulties.

One of the studies tried to explore if the type of feedback filter might affect the clinical outcome (Gillard et al., 1999). For example, a digital filter was found to be superior to its analog counterpart in terms of tremor attenuation in PD patients (84 vs. $65 \%$, respectively). Other studies proposed that a way to improve the FES system would be by implementing a control algorithm that chiefly relies on feedback from inertial sensors and EMG (Zhang and Ang, 2007; Bó et al., 2008; Widjaja et al., 2009; Rocon et al., 2010). This issue was further addressed by a group of authors who applied a new FES system consisting of hardware and software, in three ET patients, four PD patients and five healthy controls (Popović Maneski et al., 2011). In this system, two gyroscopes served the purpose of inertial sensors that provided real-time estimation of tremor, the data of which being digitized and delivered to a computer system that implements an algorithm mainly relying on a Butterworth second-order adaptive bandpass filter (Popović et al., 2010). Via a high-speed USB, the computer controls a battery-driven programmable multichannel stimulator that supports asynchronous activation of several electrodes. The latter are located over the dorsal and volar sides of the forearm, and perform a specific out-of-phase stimulation. The experimental protocol on healthy controls has proven its efficiency in activating the antagonistic muscles in a strong and asynchronous manner, which could not be voluntarily suppressed by the individuals. The intervention was beneficial in only two of the three ET patients. The current design aimed to control several upper extremity joints (fingers, wrist, elbow, and shoulder) and thus was able to overcome the limitations of the mono-joint design discussed in the first work (Javidan et al., 1992). Furthermore, it permitted the stimulation of one muscle group using multi-pad electrodes rather than the previously used single cathode, which could ensure the selectivity (PopovićBijelić et al., 2005; Popović and Popović, 2009; Popovic et al., 2009; Malešević et al., 2010b) and decrease the stimulationinduced fatigue (Popovic and Malesevic, 2009; Malešević et al., 2010a,b). Following the same principles, other studies combined FES with a brain-computer interface (Grimaldi and Manto, 2010; Rocon et al., 2010). This allows for a multimodal detection of the movement intentionality by fusing signals from EEG, EMG and kinematic sensors (in particular gyroscopes and accelerometers). Another group of authors has relied on EMG detection combined with an iterative Hilbert transform to apply FES in six patients with ET or PD (Dosen et al., 2015). In this study, the tremor was reduced by $46-81$ and $35-48 \%$ when using the motor and sensory 
stimulation, respectively, in five of the six studied patients. Thus, using electrical stimulation below motor threshold seems to be more effective than the sensory one, and prevents muscle fatigue and discomfort.

Finally, fixed-intensity FES was suggested as an alternative to the classical closed-loop FES (Bó et al., 2014). The rationale was that fixing the intensity might make the intervention more comfortable and accepted by patients. Keeping in mind that in ET, the tremor propagates from proximal to peripheral joints, this technique is intrinsically stabilizing compared to the antiphase FES stimulation, where an unstable proximal performance might increase the distal tremor. A single session of fixed-intensity FES was applied to the wrist or fingers of 10 ET patients (pulse width: $150 \mu \mathrm{s}$; frequency: $40 \mathrm{~Hz}$; with manual regulation of stimulation intensity respecting patient's feeling of discomfort). The system was similar to the previous ones in a way that it relies on inertial sensors (gyroscopes and accelerometer) and high-pass filter. Tremor was suppressed in eight patients, did not significantly change in one patient, and was exacerbated in one of them.

\section{CONCLUSION}

Although only few data are available, some of the preliminary results would pave the way for future studies on a larger scale.

Concerning NIBS, the discrepancy encountered in the results could arise from many factors. On the one hand, all of these studies had assessed the effects of different NIBS techniques in small samples (ranging from 10 to $16 \mathrm{ET}$ patients), and adopted different number of sessions (ranging from 1 to 10 consecutive daily sessions). On the other hand, the fact that ET patients represent a heterogeneous population with regard to

\section{REFERENCES}

Antal, A., Chaieb, L., Moliadze, V., Monte-Silva, K., Poreisz, C., Thirugnanasambandam, N., et al. (2010). Brain-derived neurotrophic factor (BDNF) gene polymorphisms shape cortical plasticity in humans. Brain. Stimul. 3, 230-237. doi: 10.1016/j.brs.2009.12.003

Avanzino, L., Bove, M., Tacchino, A., Ruggeri, P., Giannini, A., Trompetto, C., et al. (2009). Cerebellar involvement in timing accuracy of rhythmic finger movements in essential tremor. Eur. J. Neurosci. 30, 1971-1979. doi: 10.1111/j.1460-9568.2009.06984.x

Bagepally, B. S., Bhatt, M. D., Chandran, V., Saini, J., Bharath, R. D., Vasudev, M. K., et al. (2012). Decrease in cerebral and cerebellar gray matter in essential tremor: a voxel-based morphometric analysis under 3T MRI. J. Neuroimaging 22, 275-278. doi: 10.1111/j.1552-6569.2011.00598.x

Bain, P., Brin, M., Deuschl, G., Elble, R., Jankovic, J., Findley, L., et al. (2000). Criteria for the diagnosis of essential tremor. Neurology 4, S7.

Bending, J., and Cleeves, L. (1990). Effect of electrical nerve stimulation on dystonic tremor. Lancet 336, 1385-1386. doi: 10.1016/0140-6736(90) 92946-F

Bestmann, S., Baudewig, J., Siebner, H. R., Rothwell, J. C., and Frahm, J. (2004). Functional MRI of the immediate impact of transcranial magnetic stimulation on cortical and subcortical motor circuits. Eur. J. Neurosci. 19, 1950-1962. doi: 10.1111/j.1460-9568.2004.03277.x

Bó, A. P., Azevedo-Coste, C., Geny, C., Poignet, P., and Fattal, C. (2014). On the use of fixed-intensity functional electrical stimulation for attenuating essential tremor. Artif. Organs. 38, 984-991. doi: 10.1111/aor. 12261 the functional brain topography, tremor site, and severity, age of onset, disease duration, pharmacological interventions at the time of protocol, and the patients' sensibility to these treatments, can partly explain the subsequent variation in response to the performed NIBS interventions. In fact, the variation in preinterventional brain connectivity or genetic polymorphisms in neurotrophic factors can influence NIBS effects (Antal et al., 2010; Cárdenas-Morales et al., 2014; Nettekoven et al., 2014).

Therefore, improving the outcome of NIBS techniques in ET patients can be obtained by acting on different parameters, such as rTMS frequency, TBS pattern, or tDCS polarity. Particularly, increasing the duration or the number of stimulation sessions might enhance the therapeutic effect to a meaningful clinical level, based on the likely dose-dependent effects of these interventions (Nettekoven et al., 2014). Moreover, considering the different functional topography seen in ET patients, a smart attempt to optimize NIBS protocols would be by individualizing them. This could be achieved by performing a baseline functional neuroimaging and neurophysiological interventions in each patient. This approach would improve the definition of the optimal NIBS targets for image-guided procedures. Furthermore, future studies should not be limited to targeting M1 or the cerebellum, but rather should assess the potential value of other targets in terms of motor or cognitive improvement.

Besides acting on the disturbed central networks, peripheral stimulation constitutes a symptomatic approach that proved some benefits in ET. FES can significantly improve tremor of various etiologies, but its use is limited by its practical and esthetic profile. Finally, concerning TENS techniques, only preliminary data are available and further studies are required before drawing any conclusion.
Bó, A. P., Poignet, P., Widjaja, F., and Ang, W. T. (2008). Online pathological tremor characterization using extended Kalman filtering. Conf. Proc. IEEE Eng. Med. Biol. Soc. 2008, 1753-1756. doi: 10.1109/IEMBS.2008.4649516

Boecker, H. (2013). Imaging the role of GABA in movement disorders. Curr. Neurol. Neurosci. Rep. 13:385. doi: 10.1007/s11910-0130385-9

Boecker, H., and Brooks, D. J. (1998). Functional imaging of tremor. Mov. Disord. $13,64 \mathrm{e} 72$.

Boecker, H., Weindl, A., Brooks, D. J., Ceballos-Baumann, A. O., Liedtke, C., Miederer, M., et al. (2010). GABAergic dysfunction in essential tremor: an 11C-flumazenil PET study. J. Nucl. Med. 51, 1030-1035. doi: 10.2967/jnumed.109.074120

Bologna, M., Rocchi, L., Leodori, G., Paparella, G., Conte, A., Kahn, N., et al. (2015). Cerebellar continuous theta burst stimulation in essential tremor. Cerebellum 14, 133-141. doi: 10.1007/s12311-014-0621-0

Brittain, J. S., Cagnan, H., Mehta, A. R., Saifee, T. A., Edwards, M. J., and Brown, P. (2015). Distinguishing the central drive to tremor in Parkinson's disease and essential tremor. J. Neurosci. 35, 795-806. doi: 10.1523/JNEUROSCI.376814.2015

Britton, T. C., Thompson, P. D., Day, B. L., Rothwell, J. C., Findley, L. J., and Marsden, C. D. (1993a). Modulation of postural wrist tremors by magnetic stimulation of the motor cortex in patients with Parkinson's disease or essential tremor and in normal subjects mimicking tremor. Ann. Neurol. 33, 473-479. doi: 10.1002/ana.410330510

Britton, T. C., Thompson, P. D., Day, B. L., Rothwell, J. C., Findley, L. J., and Marsden, C. D. (1993b). Modulation of postural tremors at the wrist by supramaximal electrical median nerve shocks in essential tremor, Parkinson's 
disease and normal subjects mimicking tremor. J. Neurol. Neurosurg. Psychiatry 56, 1085-1089. doi: 10.1136/jnnp.56.10.1085

Brunoni, A. R., Nitsche, M. A., Bolognini, N., Bikson, M., Wagner, T., Merabet, L., et al. (2012). Clinical research with transcranial direct current stimulation(tDCS): challenges and future direc-tions. Brain Stimul. 5, 175-195. doi: 10.1016/j.brs.2011.03.002

Bucher, S. F., Seelos, K. C., Dodel, R. C., Reiser, M., and Oertel, W. H. (1997). Activation mapping in essential tremor with functional magnetic resonance imaging. Ann. Neurol. 41, 32-40. doi: 10.1002/ana.410410108

Buijink, A. W., Broersma, M., van der Stouwe, A. M., van Wingen, G. A., Groot, P. F., Speelman, J. D., et al. (2015). Rhythmic finger tapping reveals cerebellar dysfunction in essential tremor. Parkinsonism. Relat. Disord. 21, 383-388. doi: 10.1016/j.parkreldis.2015.02.003

Cárdenas-Morales, L., Volz, L. J., Michely, J., Rehme, A. K., Pool, E. M., Nettekoven, C., et al. (2014). Network connectivity and individual responses to brain stimulation in the human motor system. Cereb. Cortex 24, 1697-1707. doi: $10.1093 /$ cercor/bht023

Cerasa, A., Passamonti, L., Novellino, F., Salsone, M., Gioia, M. C., Morelli, M., et al. (2010). Fronto-parietal overactivation in patients with essential tremor during Stroop task. Neuroreport 21, 148-151. doi: 10.1097/WNR.0b013e328335b42c

Ceravolo, R., Salvetti, S., Piccini, P., Lucetti, C., Gambaccini, G., and Bonuccelli, U. (1999). Acute and chronic effects of clozapine in essential tremor. Mov. Disord. $14,468-472$.

Chalah, M. A., Ayache, S. S., Riachi, N., and Ahdab, R. (2015). Permanent reversal of essential tremor following a frontal lobe stroke. J. Neurol. Sci. 354, 133-134. doi: 10.1016/j.jns.2015.04.055

Choi, S. M., Kim, B. C., Chang, J., Choi, K. H., Nam, T. S., Kim, J. T., et al. (2015). Comparison of the brain volume in essential tremor and Parkinson's disease tremor using an automated segmentation method. Eur. Neurol. 73, 303-309. doi: $10.1159 / 000381708$

Chopra, A., Klassen, B. T., and Stead, M. (2013). Current clinical application of deep-brain stimulation for essential tremor. Neuropsychiatr. Dis. Treat. 9, 1859-1865. doi: 10.2147/NDT.S32342

Chuang, W. L., Huang, Y. Z., Lu, C. S., and Chen, R. S. (2014). Reduced cortical plasticity and GABAergic modulation in essential tremor. Mov. Disord. 29, 501-507. doi: 10.1002/mds. 25809

Colebatch, J. G., Findley, L. J., Frackowiak, R. S., Marsden, C. D., and Brooks, D. J. (1990). Preliminary report: activation of the cerebellum in essential tremor. Lancet 336, 1028-1030. doi: 10.1016/0140-6736(90)92489-5

Creutzfeldt, O. D., Fromm, G. H., and Kapp, H. (1962). Influence of transcortical D-C currents on cortical neuronal activity. Exp. Neurol. 5, 436-452. doi: 10.1016/0014-4886(62)90056-0

Deuschl, G., Bain, P., and Brin, M. (1998). Consensus statement of the movement disorder society on tremor. Ad hoc scientific committee. Mov. Disord. 3, S2-S23. doi: 10.1002/mds.870131303

Deuschl, G., Raethjen, J., Hellriegel, H., and Elble, R. (2011). Treatment of patients with essential tremor. Lancet Neurol. 10, 148-161. doi: 10.1016/S1474$4422(10) 70322-7$

Deuschl, G., Wenzelburger, R., Löfler, K., Raethjen, J., and Stolze, H. (2000). Essential tremor and cerebellar dysfunction clinical and kinematic analysis of intention tremor. Brain 123, 1568-1580. doi: 10.1093/brain/123.8.1568

Dietz, V., Hillesheimer, W., and Freund, H. J. (1974). Correlation between tremor, voluntary contraction, and firing pattern of motor units in Parkinson's disease. J. Neurol. Neurosurg. Psychiatry 37, 927-937. doi: 10.1136/jnnp.37.8.927

Dogu, O., Sevim, S., Camdeviren, H., Sasmaz, T., Bugdayci, R., Aral, M., et al. (2003). Prevalence of essential tremor. Door-to-door neurologic exams in Mersin Province, Turkey. Neurology 61, 1804-1806. doi: 10.1212/01.WNL.0000099075.19951.8C

Dosen, S., Muceli, S., Dideriksen, J. L., Romero, J. P., Rocon, E., Pons, J., et al. (2015). Online tremor suppression using electromyography and low-level electrical stimulation. IEEE Trans. Neural Syst. Rehabil. Eng. 23, 385-395. doi: 10.1109/TNSRE.2014.2328296

Dupuis, M. J., Evrard, F. L., Jacquerye, P. G., Picard, G. R., and Lermen, O. G. (2010). Disappearance of essential tremor after stroke. Mov. Disord. 25, 2884-2887. doi: $10.1002 / \mathrm{mds} .23328$

Elble, R. J. (2000). Diagnostic criteria for essential tremor and differential diagnosis. Neurology 4, S2-S6.
Elble, R. J., Pullman, S. L., Matsumoto, J. Y., Raethjen, J., Deuschl, G., and Tintner, R. (2006). Tremor amplitude is logarithmically related to 4- and 5-point tremor rating scales. Brain 129, 2660-2666. doi: 10.1093/brain/awl190

Eldaief, M. C., Halko, M. A., Buckner, R. L., and Pascual-Leone, A. (2011). Transcranial magnetic stimulation modulates the brain's intrinsic activity in a frequency-dependent manner. Proc. Natl. Acad. Sci. U.S.A. 108, 21229-21234. doi: $10.1073 /$ pnas. 1113103109

Elek, J., and Prochazka, A. (1989). Attenuation of wrist tremor with closed-loop electrical stimulation of muscles. J. Physiol. 414, 17P.

Fang, W., Lv, F., Luo, T., Cheng, O., Liao, W., Sheng, K., et al. (2013). Abnormal regional homogeneity in patients with essential tremor revealed by resting-state functional MRI. PLoS ONE 8:e69199. doi: 10.1371/journal.pone.0069199

Farkas, Z., Szirmai, I., and Kamondi, A. (2006). Impaired rhythm generation in essential tremor. Mov. Disord. 21, 1196-1199. doi: 10.1002/mds.20934

Ferrara, J., Stamey, W., Strutt, A. M., Adam, O. R., and Jankovic, J. (2011). Transcutaneous electrical stimulation (TENS) for psychogenic movement disorders. J. Neuropsychiatry. Clin. Neurosci. 23, 141-148. doi: 10.1176/jnp.23.2.jnp141

Filmer, H. L., Dux, P. E., and Mattingley, J. B. (2014). Applications of transcranial direct current stimulation for understanding brain function. Trends Neurosci. 37, 742-753. doi: 10.1016/j.tins.2014.08.003

Findley, L. J. (1987). "The pharmacology of essential tremor," in Movements Disorders, Vol. 2, eds C. D. Marsden and S. Fahn (London: Butterworths), 438-458.

Foerster, B. R., Nascimento, T. D., DeBoer, M., Bender, M. A., Rice, I. C., Truong, D. Q., et al. (2015). Excitatory and inhibitory brain metabolites as targets of motor cortex transcranial direct current stimulation therapy and predictors of its efficacy in fibromyalgia. Arthritis. Rheumatol. 67, 576-581. doi: 10.1002/art.38945

Galea, J. M., Jayaram, G., Ajagbe, L., and Celnik, P. (2009). Modulation of cerebellar excitability by polarity-specific noninvasive direct current stimulation. J. Neurosci. 29, 9115-9122. doi: 10.1523/JNEUROSCI.218409.2009

Gandiga, P. C., Hummel, F. C., and Cohen, L. G. (2006). TranscranialDC stimulation (tDCS): a tool for dou-ble-blindsham-controlled clinical studies in brain stimulation. Clin. Neurophysiol. 117, 845-850. doi: 10.1016/j.clinph.2005.12.003

García-Martín, E., Martínez, C., Alonso-Navarro, H., Benito-León, J., LorenzoBetancor, O., Pastor, P., et al. (2013). No association of the SLC1A2 rs3794087 allele with risk for essential tremor in the Spanish population. Pharmacogenet. Genomics 23, 587-590. doi: 10.1097/FPC.0b013e328364db9d

Gentner, R., Wankerl, K., Reinsberger, C., Zeller, D., and Classen, J. (2008). Depression of human corticospinal excitability induced by magnetic thetaburst stimulation: evidence of rapid polarity-reversing metaplasticity. Cereb. Cortex 18, 2046-2053. doi: 10.1093/cercor/bhm239

Georgiou, N., Bradshaw, J. L., Phillips, J. G., Bradshaw, J. A., and Chiu, E. (1995). Advance information and movement sequencing in Gilles de la Tourette's syndrome. J. Neurol. Neurosurg. Psychiatry 58, 184-191. doi: 10.1136/jnnp.58.2.184

Gillard, D. M., Cameron, T., Prochazka, A., and Gauthier, M. J. (1999). Tremor suppression using functional electrical stimulation: a comparison between digital and analog controllers. IEEE Trans. Rehabil. Eng. 7, 385-388. doi: $10.1109 / 86.788474$

Gironell, A. (2014). The GABA hypothesis in essential tremor: lights and shadows. Tremor. Other Hyperkinet. Mov. (N.Y.) 4:254. doi: 10.7916/D8SF2T9C

Gironell, A., Figueiras, F. P., Pagonabarraga, J., Herance, J. R., Pascual-Sedano, B., Trampal, C., et al. (2012). Gaba and serotonin molecular neuroimaging in essential tremor: a clinical correlation study. Parkinsonism. Relat. Disord. 18, 876-880. doi: 10.1016/j.parkreldis.2012.04.024

Gironell, A., Kulisevsky, J., Lorenzo, J., Barbanoj, M., Pascual-Sedano, B., and Otermin, P. (2002). Transcranial magnetic stimulation of the cerebellum in essential tremor: a controlled study. Arch. Neurol. 59, 413-417. doi: 10.1001/archneur.59.3.413

Gironell, A., Kulisevsky, J., Pascual-Sedano, B., and Flamarich, D. (2006). Effect of amantadine in essential tremor: a randomized, placebo-controlled trial. Mov. Disord. 21, 441-445. doi: 10.1002/mds.20676

Gironell, A., Martínez-Horta, S., Aguilar, S., Torres, V., Pagonabarraga, J., PascualSedano, B., et al. (2014). Transcranial direct current stimulation of the 
cerebellum in essential tremor: a controlled study. Brain Stimul. 7, 491-492. doi: 10.1016/j.brs.2014.02.001

Grefkes, C., Nowak, D. A., Wang, L. E., Dafotakis, M., Eickhoff, S. B., and Fink, G. R. (2010). Modulating cortical connectivity in stroke patients by rTMS assessed with fMRI and dynamic causal modeling. Neuroimage 50, 233-242. doi: 10.1016/j.neuroimage.2009.12.029

Grimaldi, G., and Manto, M. (2008). Tremor: From Pathogenesis to Treatment. San Rafael, CA: Mongan \& Claypool.

Grimaldi, G., and Manto, M. (2010). "Old" and emerging therapies of human tremor. Clin. Med. Insights. Ther. 2, 169-178. doi: 10.4137/CMT.S2999

Halko, M. A., Farzan, F., Eldaief, M. C., Schmahmann, J. D., and Pascual-Leone, A. (2014). Intermittent theta-burst stimulation of the lateral cerebellum increases functional connectivity of the default network. J. Neurosci. 34, 12049-12056. doi: 10.1523/JNEUROSCI.1776-14.2014

Hallett, M. (2014). Tremor: pathophysiology. Parkinsonism Relat. Disord. 20, S118-S122. doi: 10.1016/S1353-8020(13)70029-4

Hallett, M., and Dubinsky, R. M. (1993). Glucose metabolism in the brain of patients with essential tremor. J. Neurol. Sci. 114, 45-48. doi: 10.1016/0022510X(93)90047-3

Hanajima, R., Ugawa, Y., Terao, Y., Sakai, K., Furubayashi, T., Machii, K., et al. (1998). Cortico-cortical inhibition of the motor cortical area projecting to sternocleidomastoid muscle in normals and patients with spasmodic torticollis or essential tremor. Electroencephalogr. Clin. Neurophysiol. 109, 391-396. doi: 10.1016/S0924-980X(98)00036-8

Hellriegel, H., Schulz, E. M., Siebner, H. R., Deuschl, G., and Raethjen, J. H. (2012). Continuous theta-burst stimulation of the primary motor cortex in essential tremor. Clin. Neurophysiol. 123, 1010-1015. doi: 10.1016/j.clinph.2011.08.033

Helmich, R. C., Toni, I., Deuschl, G., and Bloem, B. R. (2013). The pathophysiology of essential tremor and Parkinson's tremor. Curr. Neurol. Neurosci. Rep. 13:378. doi: 10.1007/s11910-013-0378-8

Héroux, M. E., Pari, G., and Norman, K. E. (2010). The effect of contraction intensity on force fluctuations and motor unit entrainment in individuals with essential tremor. Clin. Neurophysiol. 121, 233-239. doi: 10.1016/j.clinph.2009.10.015

Huang, Y. Z. (2010). The modulation of cortical motor circuits and spinal reflexes using theta burst stimulation in healthy and dystonic subjects. Restor. Neurol. Neurosci. 28, 449-457. doi: 10.3233/RNN-2010-0554

Huang, Y. Z., Chen, R. S., Rothwell, J. C., and Wen, H. Y. (2007). The aftereffect of human theta burst stimulation is NMDA receptor dependent. Clin. Neurophysiol. 118, 1028-1032. doi: 10.1016/j.clinph.2007.01.021

Huang, Y. Z., Edwards, M. J., Rounis, E., Bhatia, K. P., and Rothwell, J. C. (2005). Theta burst stimulation of the human motor cortex. Neuron 45, 201-206. doi: 10.1016/j.neuron.2004.12.033

Javidan, M., Elek, J., and Prochazka, A. (1990). Tremor reduction by functional electrical stimulation. Neurol 40, 369 .

Javidan, M., Elek, J., and Prochazka, A. (1992). Attenuation of pathological tremors by functional electrical stimulation. II. Clinical evaluation. Ann. Biomed. Eng. 20, 225-236. doi: 10.1007/BF02368522

Jenkins, I. H., Bain, P. G., Colebatch, J. G., Thompson, P. D., Findley, L. J., Frackoviak, R. S., et al. (1993). A positron emission tomography study of essential tremor: evidence for overactivity of cerebellar connections. Ann. Neurol. 34, 82-90. doi: 10.1002/ana.410340115

Keeser, D., Meindl, T., Bor, J., Palm, U., Pogarell, O., Mulert, C., et al. (2011). Prefrontal transcranial direct current stimulation changes connectivity of resting-state networks during fMRI. J. Neurosci. 31, 15284-15293. doi: 10.1523/JNEUROSCI.0542-11.2011

Koller, W. C. (1981). Amantadine in essential tremor. Ann. Neurol. 16, 621-622. doi: 10.1002/ana.410160517

Kuhlenbäumer, G., Hopfner, F., and Deuschl, G. (2014). Genetics of essential tremor: meta-analysis and review. Neurology 82, 1000-1007. doi: 10.1212/WNL.0000000000000211

Kuo, M. F., Paulus, W., and Nitsche, M. A. (2014). Therapeutic effects of noninvasive brain stimulation with direct currents (tDCS) in neuropsychiatric diseases. Neuroimage 3, 948-960. doi: 10.1016/j.neuroimage.2013. 05.117

Lefaucheur, J. P. (2008). Principles of therapeutic use of transcranial and epidural cortical stimulation. Clin. Neurophysiol. 119, 2179-2184. doi: 10.1016/j.clinph.2008.07.007
Lefaucheur, J. P. (2009). Methods of therapeutic cortical stimulation. Neurophysiol. Clin. 39, 1-14. doi: 10.1016/j.neucli.2008.11.001

Lefaucheur, J. P. (2010). Why image-guided navigation becomes essential in the practice of transcranial magnetic stimulation. Neurophysiol. Clin. 40, 1-5. doi: 10.1016/j.neucli.2009.10.004

Lefaucheur, J. P. (2012). Neurophysiology of cortical stimulation. Int. Rev. Neurobiol. 107, 57-85. doi: 10.1016/B978-0-12-404706-8.00005-X

Lefaucheur, J. P., André-Obadia, N., Antal, A., Ayache, S. S., Baeken, C., Benninger, D. H., et al. (2014). Evidence-based guidelines on the therapeutic use of repetitive transcranial magnetic stimulation (rTMS). Clin. Neurophysiol. 125, 2150-2206. doi: 10.1016/j.clinph.2014.05.021

Liebetanz, D., Nitsche, M. A., Tergau, F., and Paulus, W. (2002). Pharmacological approach to the mechanisms of transcranial DC-stimulation-induced aftereffects of human motor cortex excitability. Brain 125, 2238-2247. doi: 10.1093/brain/awf238

Lim, S. Y., Poon, Y. Y., Chen, R., Mikulis, D., Lozano, A. M., Moro, E., et al. (2010). Marked reduction of tremor in essential tremor after putaminal infarct. J. Neurol. Neurosurg. Psychiatry 81, 1172-1173. doi: 10.1136/jnnp.2008.171223

Louis, E. D. (1999). A new twist for stopping the shakes? Revisiting GABAergic therapy for essential tremor. Arch. Neurol. 56, 807-808. doi: 10.1001/archneur.56.7.807

Louis, E. D. (2000). Essential tremor. Arch. Neurol. 57, 1522-1524. doi: 10.1001/archneur.57.10.1522

Louis, E. D. (2005). Essential tremor. Lancet Neurol. 4, 100-110. doi: 10.1016/S1474-4422(05)00991-9

Louis, E. D. (2009). Essential tremors: a family of neurodegenerative disorders? Arch. Neurol. 66, 1202-1208. doi: 10.1001/archneurol.2009.217

Louis, E. D. (2015). Medication non-adherence in essential tremor. Parkinsonism Relat. Disord. 21, 138-141. doi: 10.1016/j.parkreldis.2014.12.001

Louis, E. D., Marder, K., Cote, L., Pullman, S., Ford, B., Wilder, D., et al. (1995). Differences in the prevalence of essential tremor among elderly African Americans, whites, and Hispanics in northern Manhattan. N.Y. Arch. Neurol. 52, 1201-1205. doi: 10.1001/archneur.1995.00540360079019

Lu, M. K., Chiou, S. M., Ziemann, U., Huang, H. C., Yang, Y. W., and Tsai, C. H. (2015). Resetting tremor by single and paired transcranial magnetic stimulation in Parkinson's disease and essential tremor. Clin. Neurophysiol. doi: 10.1016/j.clinph.2015.02.010. [Epub ahead of print].

Malešević, N., Popović, L., Schwirtlich, L., and Popović, D. B. (2010a). Distributed low frequency functional electrical stimulation delays muscle fatigue compared to conventional stimulation. Muscle Nerve 42, 556-562. doi: $10.1002 /$ mus.21736

Malešević, N., Popović, L., Bijeliæ, G., and Kvašèev, G. (2010b). Muscle twitch responses for shaping the multi-pad electrode for functional electrical stimulation. J. Automatic Control 20, 53-57. doi: 10.2298/JAC1001053M

Manyam, B. V. (1984). Amantadine in essential tremor. Ann. Neurol. 9, 198-199. doi: 10.1002/ana.410090219

Micheli, F., Cersósimo, M. G., Raina, G., and Gatto, E. (2002). Quetiapine and essential tremor. Clin. Neuropharmacol. 25, 303-306. doi: 10.1097/00002826200211000-00004

Monte-Silva, K., Ruge, D., Teo, J. T., Paulus, W., Rothwell, J. C., and Nitsche, M. A. (2011). D2 receptor block abolishes $\theta$ burst stimulation-induced neuroplasticity in the human motor cortex. Neuropsychopharmacology 36, 2097-2102. doi: 10.1038/npp.2011.100

Munhoz, R. P., Hanajima, R., Ashby, P., and Lang, A. E. (2003). Acute effect of transcutaneous electrical nerve stimulation on tremor. Mov. Disord. 18, 191-194. doi: $10.1002 / \mathrm{mds} .10311$

Nahab, F. B., Peckham, E., and Hallett, M. (2007). Essential tremor, deceptively simple. Pract. Neurol. 7, 222-233. doi: 10.1136/jnnp.2007.124693

Nettekoven, C., Volz, L. J., Kutscha, M., Pool, E. M., Rehme, A. K., Eickhoff, S. B., et al. (2014). Dose-dependent effects of theta burst rTMS on cortical excitability and resting-state connectivity of the human motor system. J. Neurosci. 34, 6849-6859. doi: 10.1523/JNEUROSCI.4993-13.2014

Nitsche, M. A., Cohen, L. G., Wassermann, E. M., Priori, A., Lang, N., Antal, A., et al. (2008). Transcranial direct current stimulation: state of the art. Brain Stimul. 1, 206-223. doi: 10.1016/j.brs.2008.06.004

Nitsche, M. A., and Fregni, F. (2007). Transcranial direct current stimulation- an adjuvant tool for the treatment of neuropsychiatric disease. Curr. Psychiatry Rev. 3, 222-232. doi: 10.2174/157340007781369649 
Nitsche, M. A., Fricke, K., Henschke, U., Schlitterlau, A., Liebetanz, D., Lang, N., et al. (2003b). Pharmacological modulation of cortical excitability shifts induced by transcranial direct current stimulation in humans. J. Physiol. 553, 293-301. doi: 10.1113/jphysiol.2003.049916

Nitsche, M. A., Lampe, C., Antal, A., Liebetanz, D., Lang, N., Tergau, F., et al. (2006). Dopaminergic modulation of long-lasting direct current-induced cortical excitability changes in the human motor cortex. Eur. J. Neurosci. 23, 1651-1657. doi: 10.1111/j.1460-9568.2006.04676.x

Nitsche, M. A., Nitsche, M. S., Klein, C. C., Tergau, F., Rothwell, J. C., and Paulus, W. (2003a). Level of action of cathodal DC polarisation induced inhibition of the human motor cortex. Clin. Neurophysiol. 114, 600-604. doi: 10.1016/S1388-2457(02)00412-1

Nitsche, M. A., and Paulus, W. (2000). Excitability changes induced in the human motor cortex by weak transcranial direct current stimulation. J. Physiol. 527, 633-639. doi: 10.1111/j.1469-7793.2000.t01-1-00633.x

Nitsche, M. A., and Paulus, W. (2001). Sustained excitability elevations induced by transcranial DC motor cortex stimulation in humans. Neurology 57, 1899-1901. doi: 10.1212/WNL.57.10.1899

Nitsche, M. A., and Paulus, W. (2011). Transcranial direct current stimulationupdate 2011. Restor. Neurol. Neurosci. 29, 463-492. doi: 10.3233/RNN-20110618

Pakkenberg, H., and Pakkenberg, B. (1986). Clozapine in the treatment of tremor. Acta Neurol. Scand. 73, 295-297. doi: 10.1111/j.1600-0404.1986.tb03279.x

Paris-Robidas, S., Brochu, E., Sintes, M., Emond, V., Bousquet, M., Vandal, M., et al. (2012). Defective dentate nucleus GABA receptors in essential tremor. Brain 135, 105-116. doi: 10.1093/brain/awr301

Park, Y. G., Park, H. Y., Lee, C. J., Choi, S., Jo, S., Choi, H., et al. (2010). Ca(V)3.1 is a tremor rhythm pacemaker in the inferior olive. Proc. Natl. Acad. Sci. U.S.A. 107, 10731-10736. doi: 10.1073/pnas.1002995107

Pascual-Leone, A., Valls-Solé, J., Toro, C., Wassermann, E. M., and Hallett, M. (1994). Resetting of essential tremor and postural tremor in Parkinson's disease with transcranial magnetic stimulation. Muscle Nerve 17, 800-807. doi: 10.1002/mus.880170716

Passamonti, L., Novellino, F., Cerasa, A., Chiriaco, C., Rocca, F., Matina, M. S., et al. (2011). Altered cortical-cerebellar circuits during verbal working memory in essential tremor. Brain 134, 2274-2286. doi: 10.1093/brain/awr164

Paulus, W., Peterchev, A. V., and Ridding, M. (2013). Transcranial electric and magnetic stimulation: technique and paradigms. Handb. Clin. Neurol. 116, 329-342. doi: 10.1016/B978-0-444-53497-2.00027-9

Pinto, A. D., and Chen, R. (2001). Suppression of the motor cortex by magnetic stimulation of the cerebellum. Exp. Brain Res. 140, 505-510. doi: $10.1007 / \mathrm{s} 002210100862$

Pinto, A. D., Lang, A. E., and Chen, R. (2003). The cerebellothalamocortical pathway in essential tremor. Neurology 60, 1985-1987. doi: 10.1212/01.WNL.0000065890.75790.29

Polanía, R., Paulus, W., Antal, A., and Nitsche, M. A. (2011). Introducing graph theory to track for neuroplastic alterations in the resting human brain: a transcranial direct current stimulation study. Neuroimage 54, 2287-2296. doi: 10.1016/j.neuroimage.2010.09.085

Polanía, R., Paulus, W., and Nitsche, M. A. (2012a). Reorganizing the intrinsic functional architecture of the human primary motor cortex during rest with non-invasive cortical stimulation. PLOS ONE 7:e30971. doi: 10.1371/journal.pone.0030971

Polanía, R., Paulus, W., and Nitsche, M. A. (2012b). Modulating cortico-striatal and thalamo-cortical functional connectivity with transcranial direct current stimulation. Hum. Brain. Mapp. 33, 2499-2508. doi: 10.1002/hbm.21380

Popa, T., Russo, M., Vidailhet, M., Roze, E., Lehéricy, S., Bonnet, C., et al. (2013). Cerebellar rTMS stimulation may induce prolonged clinical benefits in essential tremor, and subjacent changes in functional connectivity: an open label trial. Brain Stimul. 6, 175-179. doi: 10.1016/j.brs.2012.04.009

Popović, D. B., and Popović, M. B. (2009). Automatic determination of the optimal shape of a surface electrode: selective stimulation. J. Neurosci. Methods 178, 174-181. doi: 10.1016/j.jneumeth.2008.12.003

Popović-Bijelić, A., Bijelić, G., Jorgovanović, N., Bojanić, D., Popović, M. B., and Popović, D. B. (2005). Multi-field surface electrode for selective electrical stimulation. Artif. Organs. 29, 448-452. doi: 10.1111/j.1525-1594.2005.29075.x

Popovic, L. Z., and Malesevic, N. M. (2009). Muscle fatigue of quadriceps in paraplegics: comparison between single vs. multi-pad electrode surface stimulation. Conf. Proc. IEEE Eng. Med. Biol. Soc. 2009, 6785-6788. doi: 10.1109 /iembs.2009.5333983

Popovic, L. Z., Malesevic, N. M., and Popovic, M. B. (2009). "Optimization of multi-pad surface electrode: selective stimulation of wrist," The IEEE Region 8 EUROCON Conference, IEEE Eurocon 2009, Saint-Petersburg, Russia. (SaintPetersburg), 142-145.

Popović, L. Z., Sekara, T. B., and Popović, M. B. (2010). Adaptive band-pass filter (ABPF) for tremor extraction from inertial sensor data. Comput. Methods Prog. Biomed. 99, 298-305. doi: 10.1016/j.cmpb.2010.03.018

Popović Maneski, L., Jorgovanović, N., Ilić, V., Došen, S., Keller, T., Popović, M. B., et al. (2011). Electrical stimulation for the suppression of pathological tremor. Med. Biol. Eng. Comput. 49, 1187-1193. doi: 10.1007/s11517-011-0803-6

Poreisz, C., Boros, K., Antal, A., and Paulus, W. (2007). Safety aspects of transcranial direct current stimula-tion concerning healthy subjects and patients. Brain Res. Bull. 72, 208-214. doi: 10.1016/j.brainresbull.2007.01.004

Priori, A. (2003). Brain polarization in humans: a reappraisal of an old tool for prolonged non-invasive modulation of brain excitability. Clin. Neurophysiol. 114, 589-595. doi: 10.1016/S1388-2457(02)00437-6

Priori, A., Berardelli, A., Rona, S., Accornero, N., and Manfredi, M. (1998). Polarization of the human motor cortex through the scalp. Neuroreport 9, 2257-2260. doi: 10.1097/00001756-199807130-00020

Prochazka, A., Elek, J., and Javidan, M. (1992). Attenuation of pathological tremors by functional electrical stimulation. I. Method. Ann. Biomed. Eng. 20, 205-224. doi: 10.1007/BF02368521

Purpura, D. P., and McMurtry, J. G. (1965). Intracellular activities and evoked potential changes during po-larization of motor cortex. J. Neurophysiol. 28, 166-185.

Quattrone, A., Cerasa, A., Messina, D., Nicoletti, G., Hagberg, G. E., Lemieux, L., et al. (2008). Essential head tremor is associated with cerebellar vermis atrophy: a volumetric and voxel-based morphometry MR imaging study. Am. J. Neuroradiol. 29, 1692-1697. doi: 10.3174/ajnr.a1190

Raethjen, J., and Deuschl, G. (2012). The oscillating central network of Essential tremor. Clin. Neurophysiol. 123, 61-64. doi: 10.1016/j.clinph.2011.09.024

Raethjen, J., Govindan, R., Kopper, F., Muthuraman, M., and Deuschl, G. (2007). Cortical involvement in the generation of essential tremor. J. Neurophysiol. 97, 3219-3228. doi: 10.1152/jn.00477.2006

Rao, S. M., Mayer, A. R., and Harrington, D. L. (2001). The evolution of brain activation during temporal processing. Nat. Neurosci. 4, 317-323. doi: $10.1038 / 85191$

Rocon, E., Gallego, J. A., Barrios, L., Victoria, A. R., Ibanez, J., Farina, D., et al. (2010). Multimodal BCI-mediated FES suppression of pathological tremor. Conf. Proc. IEEE Eng. Med. Biol. Soc. 2010, 3337-3340. doi: 10.1109/iembs.2010.5627914

Romeo, S., Berardelli, A., Pedace, F., Inghilleri, M., Giovannelli, M., and Manfredi, M. (1998). Cortical excitability in patients with essential tremor. Muscle Nerve 21, 1304-1308.

Ross, J. P., Rayaprolu, S., Bernales, C. Q., Soto-Ortolaza, A. I., van Gerpen, J., Uitti, R. J., et al. (2014). SLC1A2 rs3794087 does not associate with essential tremor. Neurobiol. Aging 35, e9-e10. doi: 10.1016/j.neurobiolaging.2013.09.022

Schneider, S. A., and Deuschl, G. (2014). The treatment of tremor. Neurotherapeutics 11, 128-138. doi: 10.1007/s13311-013-0230-5

Schnitzler, A., Münks, C., Butz, M., Timmermann, L., and Gross, J. (2009). Synchronized brain network associated with essential tremor as revealed by magnetoencephalography. Mov. Disord. 24, 1629-1635. doi: $10.1002 / \mathrm{mds} .22633$

Shill, H. A., Adler, C. H., Beach, T. G., Lue, L. F., Caviness, J. N., Sabbagh, M. N., et al. (2012). Brain biochemistry in autopsied patients with essential tremor. Mov. Disord. 27, 113-117. doi: 10.1002/mds.24004

Shin, D. H., Han, B. S., Kim, H. S., and Lee, P. H. (2008). Diffusion tensor imaging in patients with essential tremor. Am. J. Neuroradiol. 29, 151-153. doi: 10.3174/ajnr.A0744

Shin, H., Lee, D. K., Lee, J. M., Huh, Y. E., Youn, J., Louis, E. D., et al. (2015) Atrophy of the cerebellar vermis in essential tremor: segmental volumetric MRI analysis. Cerebellum. doi: 10.1007/s12311-015-0682-8. [Epub ahead of print].

Shukla, G., Bhatia, M., Pandey, R. M., and Behari, M. (2003). Cortical silent period in essential tremor. Electromyogr. Clin. Neurophysiol. 43, 329-333.

Silvanto, J., Muggleton, N. G., Cowey, A., and Walsh, V. (2007). Neural activation state determines behavioral susceptibility to modified theta burst transcranial 
magnetic stimulation. Eur. J. Neurosci. 26, 523-528. doi: 10.1111/j.14609568.2007.05682.x

Sluka, K. A., and Walsh, D. (2003). Transcutaneous electrical nerve stimulation: basic science mechanisms and clinical effectiveness. J. Pain 4, 109-121. doi: 10.1054/jpai.2003.434

Stagg, C. J., Best, J. G., Stephenson, M. C., O’Shea, J., Wylezinska, M., Kincses, Z. T., et al. (2009). Polarity-sensitive modulation of cortical neurotransmitters by transcranial stimulation. J. Neurosci. 29, 5202-5206. doi: 10.1523/JNEUROSCI.4432-08.2009

Tan, E. K., Foo, J. N., Tan, L., Au, W. L., Prakash, K. M., Ng, E., et al. (2013). SLC1A2 variant associated with essential tremor but not Parkinson disease in Chinese subjects. Neurology 80, 1618-1619. doi: 10.1212/WNL.0b013e31828f1903

Teo, J. T., Swayne, O. B., and Rothwell, J. C. (2007). Further evidence for NMDA-dependence of the after-effects of human theta burst stimulation. Clin. Neurophysiol. 118, 1649-1651. doi: 10.1016/j.clinph.2007.04.010

Thier, S., Lorenz, D., Nothnagel, M., Poremba, C., Papengut, F., Appenzeller, S., et al. (2012). Polymorphisms in the glial glutamate transporter SLC1A2 are associated with essential tremor. Neurology. 79, 243-248. doi: 10.1212/WNL.0b013e31825fdeed

Thompson, P. D., Dick, J. P., Day, B. L., Rothwell, J. C., Berardelli, A., Kachi, T., et al. (1986). Electrophysiology of the corticomotoneurone pathways in patients with movement disorders. Mov. Disord. 1, 113-117. doi: $10.1002 / \mathrm{mds} .870010205$

Tinazzi, M., Farina, S., Bhatia, K., Fiaschi, A., Moretto, G., Bertolasi, L., et al. (2005b). TENS for the treatment of writer's cramp dystonia: a randomized, placebo-controlled study. Neurology 64, 1946-1948. doi: 10.1212/01.WNL.0000163851.70927.7E

Tinazzi, M., Zarattini, S., Valeriani, M., Romito, S., Farina, S., Moretto, G., et al. (2005a). Long-lasting modulation of human motor cortex following prolonged transcutaneous electrical nerve stimulation (TENS) of forearm muscles: evidence of reciprocal inhibition and facilitation. Exp. Brain Res. 161, 457-464. doi: 10.1007/s00221-004-2091-y

Tinazzi, M., Zarattini, S., Valeriani, M., Stanzani, C., Moretto, G., Smania, N., et al. (2006). Effects of transcutaneous electrical nerve stimulation on motor cortex excitability in writer's cramp: neurophysiological and clinical correlations. Mov. Disord. 21, 1908-1913. doi: 10.1002/mds.21081

Valchev, N., Ćurčić-Blake, B., Renken, R. J., Avenanti, A., Keysers, C., Gazzola, V., et al. (2015). cTBS delivered to the left somatosensory cortex changes its functional connectivity during rest. Neuroimage 114, 386-397. doi: 10.1016/j.neuroimage.2015.04.017

Widjaja, F., Shee, C. Y., Poignet, P., and Ang, W. T. (2009). Filtering of intended motion for real-time tremor compensation in human upper limb using surface electromyography. Conf. Proc. IEEE Eng. Med. Biol. Soc. 2009, 2996-2999. doi: 10.1109/iembs.2009.5332523

Wills, A. J., Jenkins, I. H., Thompson, P. D., Findley, L. J., and Brooks, D. J. (1995). A positron emission tomography study of cerebral activation associated with essential and writing tremor. Arch. Neurol. 52, 299-305. doi: 10.1001/archneur.1995.00540270095025

Wischnewski, M., and Schutter, D. J. (2015). Efficacy and time course of theta burst stimulation in healthy humans. Brain Stimul. 8, 685-692. doi: 10.1016/j.brs.2015.03.004

Yetimalar, Y., Irtman, G., Gürgör, N., and Basoglu, M. (2003). Olanzapine efficacy in the treatment of essential tremor. Eur. J. Neurol. 10, 79-82. doi: 10.1046/j.1468-1331.2003.00534.x

Yetimalar, Y., Irtman, G., Kurt, T., and Basoglu, M. (2005). Olanzapine versus propranolol in essential tremor. Clin. Neurol. Neurosurg. 108, 32-35. doi: 10.1016/j.clineuro.2005.01.002

Yu, H. Y., Chen, J. T., Lee, Y. C., Guo, Y. C., Kao, C. D., Shan, D. E., et al. (2001) Single-pulse transcranial magnetic stimulation reset the rhythm of essential tremor but not heart beat. Zhonghua Yi Xue Za Zhi 64, 271-276.

Yu, S. W., Chen, C. M., Chen, Y. C., Chang, C. W., Chang, H. S., Lyu, R. K., et al. (2013). SLC1A2 variant is associated with essential tremor in Taiwanese population. PLoS ONE 8:e71919. doi: 10.1371/journal.pone.0071919

Zesiewicz, T. A., Sullivan, K. L., Hinson, V., Stover, N. P., Fang, J., Jahan, I., et al. (2013). Multisite, double-blind, randomized, controlled study of pregabalin for essential tremor. Mov. Disord. 28, 249-250. doi: 10.1002/mds.25264

Zesiewicz, T. A., Ward, C. L., Hauser, R. A., Salemi, J. L., Siraj, S., Wilson, M. C., et al. (2007). A pilot, double-blind, placebo-controlled trial of pregabalin (Lyrica) in the treatment of essential tremor. Mov. Disord. 22, 1660-1663. doi: $10.1002 / \mathrm{mds} .21629$

Zhang, D., and Ang, W. T. (2007). Reciprocal EMG controlled FES for pathological tremor suppression of forearm. Conf. Proc. IEEE Eng. Med. Biol. Soc. 2007, 4810-4813. doi: 10.1109/IEMBS.2007.4353416

Conflict of Interest Statement: The authors declare that the research was conducted in the absence of any commercial or financial relationships that could be construed as a potential conflict of interest.

Copyright (C) 2015 Chalah, Lefaucheur and Ayache. This is an open-access article distributed under the terms of the Creative Commons Attribution License (CC BY). The use, distribution or reproduction in other forums is permitted, provided the original author(s) or licensor are credited and that the original publication in this journal is cited, in accordance with accepted academic practice. No use, distribution or reproduction is permitted which does not comply with these terms. 